\title{
Evaluating Diagnostic and Pharmacologic Management Cost of Chronic Abdominal Pain and Chronic Constipation in Iranian Children
}

\author{
Seyed Mohsen Dehghani ${ }^{1^{*}}$, Mohammad Hadi Imanieh ${ }^{1}$, Naser Honar ${ }^{1}$, Ahmad Ghaniza- \\ deh $^{2}$, Seyedeh Shazia Rizvi ${ }^{3}$
}

${ }^{1}$ Department of Pediatric Gastroenterology, Shiraz Transplant Research Center, Gastroenterohepatology Research Center, Shiraz University of Medical Sciences, Shiraz, IR Iran

2 Department of Pediatric Psychiatry, Shiraz University of Medical Sciences, Shiraz, IR Iran

${ }^{3}$ Gastroenterohepatology Research Center, Shiraz University of Medical Sciences, Shiraz, IR Iran

* Corresponding author: Seyed Mohsen Dehghani, Department of Pediatric Gastroenterology, Shiraz Transplant Research Center, Gastroenterohepatology Research Center, Shiraz University of Medical Sciences, Shiraz, IR Iran.Tel.: +98-7116261775, Fax:+98-7116474298, E-mail: dehghanism@sums.ac.ir

\begin{abstract}
A B S T R A C T
Background:Abdominal pain and constipation are the most common symptoms in children and because of lacking a well-defined diagnostic criteria for these symptoms various aspect of medical care in these patients are increased.

objectives: The current study aimed to evaluate the number and the cost of diagnostic and pharmacologic management of chronic abdominal pain and chronic constipation in children aged less than 18 years managed by general physicians or pediatricians before the patient is examined by pediatric gastroenterologist.

Patients and Methods: In a cross-sectional study a sample of 91 consecutive patients with chronic abdominal pain and chronic constipation aged less than 18 years managed by pediatricians and general physicians were interviewed, examined and a questionnaires (based on the Rome III criteria) were filled, before they visited a pediatric gastroenterologist in an outpatient gastroenterology clinic. Cost and number of pharmacologic management and paraclinical workups done were calculated in total for the two symptoms separately.

Results: There were 91 patients, among which 55 (60.4\%) had come with chronic abdominal pain and 36 (39.6\%) had come with chronic constipation. The calculated cost per case for general physician and pediatrician visits and paraclinical and pharmacological management for patients with chronic abdominal pain was $\$ 65.1$ and for chronic constipation was $\$$ 53.2. For chronic abdominal pain cost per case for general physician visit was $\$ 8.6$, for pediatricians was $\$ 26.9$, for paraclinical management was $\$ 27.7$ and for pharmacological management was $\$ 1.9$. Similarly for the patients with chronic constipation cost per case for general physician visit was $\$ 14.8$, for pediatricians was $\$ 28.1$, for paraclinical management was \$7.7, and for pharmacological management was \$2.6.

Conclusions: This study suggests that symptoms like chronic abdominal pain, and chronic constipation seem to put a heavy burden on the economy of the country, so training programs for pediatricians and general physicians that can well train them to handle such symptoms may decrease the number of clinical visits, repetitive investigation procedures, and utilizing multiple prescription drugs. Also media, magazines, booklets in hospitals, clinics and drug stores can help to educate parents and they in turn can cooperate better with the physician and will cope with long term symptoms of such problems in their children better.
\end{abstract}

Keywords: Costs and Cost Analysis, Abdominal Pain, Constipation

Article type: Research Article; Received: 28 Feb 2012, Revised: 02 Aug 2012, Accepted:06 Aug 2012. DOI: 10.17795/compreped-4479

Implication for health policy/practice/research/medical education:

Medical economy is important for health education programing.

-Please cite this paper as:

Dehghani SM, Imanieh MH, Honar N, Ghanizadeh A, Rizvi Sh. Evaluating Diagnostic and Pharmacologic Management Cost of Chronic Abdominal Pain and Chronic Constipation in Iranian Children. J Compr Ped. 2013:4(1):66-71.

Copyright (C) 2013, Iranian Society of Pediatrics.

This is an Open Access article distributed under the terms of the Creative Commons Attribution License, which permits unrestricted use, distribution, and reproduction in any medium, provided the original work is properly cited. 


\section{Background}

Chronic abdominal pain and chronic constipation are among the most common complaints in children. Rome III criteria for chronic abdominal pain includes all of the following: "persistent or recurrent pain or discomfort centered in the upper abdomen (above the umbilicus), not relieved by defecation or associated with the onset of a change in stool frequency or stool form (i.e., not irritable bowel syndrome), and no evidence of an inflammatory, anatomic, metabolic or neoplastic process that explains the subject's symptoms. Criteria fulfilled at least once per week for at least 2 months prior to diagnosis" (1). Chronic abdominal pain is a common symptom in children that is managed by primary care physicians, medical subspecialists, and surgical specialists (2). Most children with chronic abdominal pain who refer to the primary care physicians don't need diagnostic work up (2).

Chronic constipation is also one of the most common reasons to consult a pediatrician. Functional constipation is the cause in $97 \%$ of children, that diagnosis is confirmed by history and physical examination, and multiple diagnostic testing is unlikely to be required (3). Rome III criteria to diagnose chronic constipation include two or more of the following in a child with a developmental age of at least 4 years with insufficient criteria for diagnosis of irritable bowel syndrome: "two or fewer defecations in the toilet per week, at least one episode of fecal incontinence per week, history of retentive posturing or excessive volitional stool retention, history of painful or hard bowel movements, presence of a large fecal mass in the rectum, and history of large diameter stools. Criteria fulfilled at least once per week for at least 2 months prior to diagnosis" (1). Multiple studies were done and estimated the total health care utilization and costs for children with abdominal pain and/or constipation. These investigations demonstrated that childhood abdominal pain and constipation had a significant impact on the use and cost of medical care services (4-10).

Also, the cost of diagnostic procedures, laboratory work ups, advanced medical evaluations including subspecialty consultations, hospital admission, lost work days for parents, and babysitter fees may be significant $(9,10)$.

\section{Objectives}

The current study was the first study which aimed to evaluate the number and the cost of diagnostic and pharmacologic management of chronic abdominal pain and chronic constipation in Iranian children managed by general physicians or pediatricians before the patient was examined by pediatric gastroenterologist.

\section{Patients and Methods}

It was a cross-sectional study in which a sample of 91 consecutive patients with chronic abdominal pain and chronic constipation aged less than 18 years managed by pediatricians and general physicians before they visited a pediatric gastroenterologist in an outpatient Gastroenterology Clinic affiliated to Shiraz University of Medical Sciences between March and September 2009 were enrolled.

The diagnosis of chronic abdominal pain and chronic constipation were made according to Rome III criteria (1). Patients who had not been visited by pediatrician or general physician and had directly come to pediatric gastroenterologist were excluded from the study.

A questionnaire was used to record data which consisted of questions about paraclinical workups and pharmacologic management done and the number of general physicians and pediatricians visited. Standards for costs of paraclinical workups, general physician, and pediatrician visits was based on a booklet about public and private prices of year 2009 provided by dean of health service. Patients were asked about the previous laboratory tests done, and medications bought before. Also previous laboratory records and medications with them were checked and all of them were correlated with the prescription on pages of insurance card of the patient. The total number of times that medications prescribed and management done, and the total number of visits of general physicians and pediatricians were calculated for each patient and the data was also used to calculate cost per case in each group. Also, the cost and number of pharmacologic management and paraclinical workups done were calculated in total for these two symptoms.

For all patients minimum accepted duration of medical therapy by antibiotics was 7 days, by $\mathrm{H} 2$ receptor inhibitors and proton pump inhibitors (PPIs) was 4 weeks and medications for symptomatic therapy were considered only 10 tablets each time. Also while considering the cost of syrups, if they were in different concentrations with different costs, the mean was taken as price. All the costs were presented as Purchasing Power Parity (PPP) dollar or international dollar (i.e., estimated to be equal to 10540 Iranian Rials).

\section{Results}

In the current study the total number of patients were 91 among which 55 (60.4\%) had come with chronic abdominal pain and 36 (39.6\%) had come with chronic constipation. Chronic abdominal pain was significantly more common in girls $(38 / 55 ; 69.1 \%)(\mathrm{P}<0.001)$ whereas chronic constipation was seen more in boys (21/36; 58.3\%), but not statistically significant $(\mathrm{P}=0.162)$. The mean age of children with chronic abdominal pain and chronic constipation were $7.1 \pm 3.4$ year and $6.3 \pm 2.7$ year, respectively. In chronic abdominal pain the highest number of visits were for general physicians (157) and pediatricians (189). The number of visits per case in chronic abdominal pain for general physician was 3.6 times and for pediatricians was 4.9 times. Similarly for chronic constipation there were 130 visits for general physicians and 149 visits 
for pediatricians. The number of visits per case in chronic constipation for general physicians was 6.2 times and for pediatricians was 5.1 times. The calculated cost per case for paraclinical workups and pharmacologic management and general physician and pediatrician visits for patients with chronic abdominal pain and chronic constipation are shown in (Table 1 ).

In chronic abdominal pain the most commonly used paraclinical workups were stool OB (87.3\%) and stool OP (87.3\%), and in chronic constipation were urine analysis (47.2\%) and urine culture (44.4\%). Most common medications used in chronic abdominal pain were metronidazole (49.1\%) and ranitidine (36.4\%), and in chronic constipation were bisacodyl suppository (47.2\%) and $\mathrm{MgOH}$ syrup (38.9\%) (Table 2-3).

Table 1. Total Costs per Case for General Physician and Pediatrician Visits, Paraclinical Workups and Pharmacological Management Done in Chronic Abdominal Pain and Chronic Constipation ${ }^{\mathrm{a}}$

\begin{tabular}{lll}
\hline & Abdominal Pain & Constipation \\
\hline $\begin{array}{l}\text { Paraclinical } \\
\text { workups }\end{array}$ & 27.7 & 7.7 \\
$\begin{array}{l}\text { Pharmacologic } \\
\text { therapy }\end{array}$ & 1.9 & 2.6 \\
\hline $\begin{array}{l}\text { General } \\
\text { physician visits }\end{array}$ & 8.6 & 14.8 \\
$\begin{array}{l}\text { Pediatricians } \\
\text { visits }\end{array}$ & 26.9 & 28.1 \\
$\begin{array}{l}\text { Total cost per } \\
\text { case }\end{array}$ & 65.1 & 53.2 \\
\hline
\end{tabular}

a All costs are in PPP\$ [Purchasing Power Parity dollar or international dollar (i.e., estimated to be equal to 10540 Iranian Rials)]

Among the patients who had come with chronic abdominal pain 5 (9.1\%) were those for whom no paraclinical workup was done at all, and they only received pharmacological management, similarly 5 (9.1\%) patients were those for whom only paraclinical workup was done without any medication. Moreover, among the patients who had come with chronic constipation 11 (30.5\%) were those for whom no paraclinical workup was done at all and only received pharmacological management, also 5 (13.9\%) patients were those for whom only paraclinical workup was done without any medication. Three (8.3\%) were those patients for whom neither paraclinical workup was done nor any medication was prescribed and 2 (5.5\%) patients were those for whom only diet therapy was suggested. Six (10.9\%) patients had hospital admissions. Forty-three (78.2\%) of 55 patients with chronic abdominal pain had 157 general physicians' visits and 38 (69.1\%) patients had 189 pediatricians' visits. Number of visits per case for general physicians was 3.6 times and for pediatricians was 4.9 times. Cost per case for general physician visits was $\$ 8.6$, and for pediatricians`visits was $\$ 26.9$. Total costs for patients who did paraclinical work- ups and received medications among 55 patients with chronic abdominal pain are shown in (Table 2). Thirtysix (39.6\%) patients had come with chronic constipation. Three (8.3\%) patients had hospital admissions. Twentyone (58.3\%) patients had 130 general physicians' visits and 29 (80.5\%) patients had 149 pediatricians' visits. The number of visits per case for general physicians was 6.2 times and for pediatricians was 5.1 times. Cost per case for general physicians `visits was $\$ 14.8$ and for pediatricians' visits was \$28.1. Total costs for patients who did paraclinical workups and received medications among 36 patients with chronic constipation are shown in (Table 3).

\section{Discussion}

Chronic abdominal pain and chronic constipation are the most common complaints in pediatric age group. Several studies have revealed that chronic abdominal pain is a common symptom in children managed by primary care physicians, medical subspecialists, and surgical specialists $(2,8)$. Although children with chronic abdominal pain and their parents usually have anxiety and depression, presence of these psychiatric or painful family problems cannot differentiate between functional and organic causes of chronic abdominal pain. Most children with chronic abdominal pain who refer to the primary care physicians don't need diagnostic workup (2). About chronic constipation, studies showed that the prevalence rate for chronic constipation in the first year of life was $2.9 \%$, and in the second year of life, the rate was $10.1 \%$. Chronic functional constipation was the cause in $97 \%$ of the children. Boys and girls were affected by equal frequency (3). In a study in the United States, the data collected from two consecutive years of the Medical Expenditure Panel Survey (MEPS) was evaluated and all children with constipation according to their parents' reports or those received a prescription for laxatives in a given year were identified. In this study the outcome measures included service utilization and expenditures. This database included a total of 21778 children aged less than 18 years, representing 158 million children nationally. During the two-year period an estimated 1.7 million US children $(1.1 \%)$ reported to have had constipation. There were no significant differences regarding age, sex, race, and socioeconomic status between constipated children and those without constipation. The constipated children used more health services than those without constipation, resulting in significantly higher costs: \$3430/ year vs $\$ 1099$ /year respectively. This amounts to an additional cost for constipated children of $\$ 3.9$ billion /year. This study showed that pediatric constipation had a significant impact on the use and cost of medical care services. According to this study the estimated cost per year in constipated children in the United States is 3 times higher than those without constipation, which is likely an underestimate of the actual cost of pediatric consti- 
pation (7). Another investigation revealed patterns and costs of chronic abdominal pain in South American children. In this study during a four-year period, diagnoses of all house calls were evaluated. A total of 125,945 in-home visits and 1588 outpatient consultations were investigated. For chronic abdominal pain the consultation rates were highest among children between 7 to 9 years of age. These consultation rates for chronic abdominal pain in female children between 9 to 14 years of age were significantly higher than those of male subjects in the same age group. The average consultation rate for chronic abdominal pain was approximately $3.8 \%$ of the per capita health care spending in Uruguay in 2005 (4). Another study in North Carolina revealed that chronic abdominal pain accounts for $5 \%$ of pediatrician visits and continues to be a challenging and time-consuming concern.

\begin{tabular}{|c|c|c|c|c|c|}
\hline $\begin{array}{l}\text { Paraclinical } \\
\text { Workup }\end{array}$ & Patients, No. & Total Cost & $\begin{array}{l}\text { Pharmacological } \\
\text { Management }\end{array}$ & Patients, No. & Total Cost \\
\hline $\begin{array}{l}\text { Abdominal } \\
\text { sonography }\end{array}$ & 26 & 175.2 & Metronidazole & 27 & 8.9 \\
\hline Stool OB & 48 & 20.2 & Erythromycin & 2 & 2.8 \\
\hline Stool OP & 48 & 30.3 & Amoxicillin & 3 & 1.2 \\
\hline Stool culture & 14 & 66.5 & $\mathrm{MgOH}$ & 10 & 4.2 \\
\hline Urine analysis & 35 & 10.5 & Bismuth & 2 & 0.9 \\
\hline Urine culture & 40 & 58 & Dicyclomine & 17 & 1.8 \\
\hline Upper endoscopy & 9 & 540 & Clidinium-C & 3 & 0.9 \\
\hline СBC & 31 & 46.7 & C-lax tablet & 1 & 0.4 \\
\hline Urea breath test & 1 & 2.9 & Omeprazole & 12 & 13.7 \\
\hline Abdominal x-ray & 4 & 31.5 & Ranitidine & 20 & 15.1 \\
\hline LFT & 14 & 69.3 & Cimetidine & 7 & 12.1 \\
\hline ESR & 5 & 1 & Belladona & 3 & 4 \\
\hline $\begin{array}{l}\text { IgA and IgG } \\
\text { H.pylori }\end{array}$ & 4 & 19.5 & Famotidine & 5 & 5 \\
\hline Fe, TIBC & 2 & 4.8 & Dimethicone & 10 & 1 \\
\hline TFT & 4 & 32.8 & Cefixime & 7 & 16.1 \\
\hline Ca, Ph & 2 & 10.7 & Piperazine & 1 & 0.4 \\
\hline $\begin{array}{l}\text { Diagnostic } \\
\text { laparoscopy }\end{array}$ & 1 & 33.8 & Metoclopramide & 8 & 0.4 \\
\hline IVP & 1 & 39.1 & Ondansetron & 1 & 0.1 \\
\hline BUN, Cr, Na, Ka & 6 & 15.3 & Furazolidone & 2 & 1.5 \\
\hline Blood culture & 1 & 3.3 & Hyoscine & 3 & 1.3 \\
\hline KUB sonography & 1 & 7.1 & Ciprofloxacin & 1 & 0.8 \\
\hline T.G, Cholesterol & 2 & 3.6 & Indomethacin & 1 & 0.2 \\
\hline Pelvic sonography & 2 & 23.4 & Cephalexin & 1 & 1.1 \\
\hline Echocardiography & 2 & 33 & Mebendazole & 5 & 0.1 \\
\hline CRP & 2 & 1.5 & Nalidixic acid & 1 & 0.6 \\
\hline $\begin{array}{l}\text { Color Doppler of } \\
\text { ovaries }\end{array}$ & 1 & 89.3 & Parrafine oil & 1 & 0.4 \\
\hline Wrights test & 1 & 1.2 & Gripe mixture & 1 & 0.1 \\
\hline Widal test & 1 & 2 & $\begin{array}{l}\text { Bisacodyl } \\
\text { suppository }\end{array}$ & 1 & 0.5 \\
\hline $\begin{array}{l}\text { Abdominal pelvic } \\
\text { CT Scan }\end{array}$ & 2 & 200.2 & & & \\
\hline
\end{tabular}

Abbreviations: BUN, blood urea nitrogen; CBC, complete blood count; CRP, C-reactive protein; ESR, erythrocyte sedimentation rate; H. pylori, Helicobacter pylori; IVP, intravenous pyelogram; KUB, kidney, ureter bladder; LFT, liver function test; Stool OB, stool occult blood; Stool OP, stool ova and parasites; TFT, thyroid function tests; T.G. cholesterol, triglycerides cholesterol; TIBC, Total Iron Binding Capacity

${ }^{a}$ All costs are in PPP\$ [Purchasing Power Parity dollar or international dollar (i.e., estimated to be equal to 10540 Iranian Rials)] 


\begin{tabular}{|c|c|c|c|c|c|}
\hline $\begin{array}{l}\text { Paraclinical } \\
\text { Management }\end{array}$ & $\begin{array}{l}\text { Number of } \\
\text { Patients }\end{array}$ & Total $\operatorname{Cos}^{\mathrm{a}}$ & $\begin{array}{l}\text { Paraclinical } \\
\text { Management }\end{array}$ & $\begin{array}{l}\text { Number of } \\
\text { Patients }\end{array}$ & Total Cost ${ }^{\mathrm{a}}$ \\
\hline $\begin{array}{l}\text { Abdominal } \\
\text { sonography }\end{array}$ & 8 & 53.9 & Metronidazole & 3 & 1 \\
\hline Stool OB & 16 & 6.7 & Erythromycin & 1 & 1.4 \\
\hline Stool OP & 16 & 10.1 & $\mathrm{MgOH}$ & 14 & 5.9 \\
\hline Stool culture & 6 & 28.5 & Dicyclomine & 2 & 0.2 \\
\hline Urine analysis & 17 & 5.1 & Omeprazole & 2 & 2.3 \\
\hline Urine culture & 16 & 23.2 & Ranitidine & 3 & 2.3 \\
\hline СВC & 14 & 21.1 & Dimethicone & 1 & 0.1 \\
\hline Abdominal x-ray & 5 & 39.4 & Metoclopramide & 2 & 0.1 \\
\hline LFT & 2 & 9.9 & Parrafine oil & 2 & 0.8 \\
\hline ESR & 1 & 0.2 & $\begin{array}{l}\text { Bisacodyl } \\
\text { suppository }\end{array}$ & 17 & 8.5 \\
\hline Fe, TIBC & 1 & 2.4 & Lactulose & 8 & 23.2 \\
\hline TFT & 1 & 8.2 & PEG & 8 & 27.8 \\
\hline $\mathrm{Ca}, \mathbf{P h}$ & 2 & 10.7 & Senna & 13 & 14.3 \\
\hline BUN, Cr, Na, Ka & 2 & 5.1 & Fijan Syrup & 3 & 4.3 \\
\hline Wrights test & 1 & 1.2 & $\begin{array}{l}\text { Antihemorrhoid } \\
\text { ointment }\end{array}$ & 2 & 1.2 \\
\hline Widal test & 1 & 2 & $\begin{array}{l}\text { Glycerin } \\
\text { suppository }\end{array}$ & 1 & 0.1 \\
\hline Barium enema & 3 & 72.1 & & & \\
\hline
\end{tabular}

Abbreviations: BUN, blood urea nitrogen; CBC, complete blood count; CRP, C-reactive protein; ESR, erythrocyte sedimentation rate; H. pylori, Helicobacter pylori; IVP, intravenous pyelogram; KUB, kidney, ureter bladder; LFT, liver function test; Stool OB, stool occult blood; Stool OP, stool ova and parasites; TFT, thyroid function tests; T.G. cholesterol, triglycerides cholesterol; TIBC, Total Iron Binding Capacity

a All costs are in PPP\$ [Purchasing Power Parity dollar or international dollar (i.e., estimated to be equal to 10540 Iranian Rials)]

Multiple diagnostic tests may be painful and useless and the cost of diagnostic procedures, laboratory workup, advanced medical evaluations including subspecialty consultations, hospital admission, parents' lost work days, and babysitter fees may be significant (8).

The two symptoms are expected to be of remarkable economic burden because of their chronic nature. Chronicity and the vagueness of the symptoms may lead the physician more frequently to order paraclinical and imaging tests or try some courses of experimental treatment and therefore the pattern of frequent clinical visits, repetitive investigation procedures and utilization of multiple prescription and non-prescription drugs which increase the costs.

As indicated in the results of the present study there are a large number of visits to general physicians and pediatricians before they reach a pediatric gastroenterologist. So, repeated clinical visits lead to repeated management and increase in costs. Although in the current study nonmedical direct costs such as transportation and direct medical costs such as hoteling of hospital admissions were not taken into consideration.

To avoid the unnecessary, expensive and repeated inves- tigations, strategies should be evaluated based on their clinical efficacy, and cost effectiveness. Physicians managing patients should initiate appropriate treatment by educating the parents about the chronicity of the symptoms and appropriate use of medications. The informed parents may experience less stress and fear which may in turn help them cope with long term symptoms better. These steps play an important role in establishing a positive physician parent relationship and therefore better results. Also most of the tests recommended for initial diagnosis such as blood tests, urine tests and stool tests should not be repeated if the patient has the earlier recent reports and the diagnosis is also clear. Physicians should have a good communication with the pediatric gastroenterologists to whom they refer the patients. Such communication can prevent duplication of tests.

In conclusion the current study suggests that symptoms like chronic abdominal pain and chronic constipation seem to put a heavy burden on the economy of the country, so training programs for pediatricians and general physicians that can well train them to handle such symptoms, may decrease the number of clinical visits, repetitive investigation procedures, and utilization of mul- 
tiple prescription drugs. Also media, magazines, booklets available in hospitals, clinics and drug stores, can help to educate parents and they in turn can cooperate better with the physician and will cope with long term symptoms of their children better.

\section{Acknowledgements}

The present article was extracted from the thesis written by Seyedeh Shazia Rizvi and was financially supported by Shiraz University of Medical Sciences grants No 87-4509.

\section{Financial Disclosure}

None declared.

\section{Funding/Support}

None declared.

\section{Authors' Contribution}

None declared.

\section{References}

1. Rasquin A, Di Lorenzo C, Forbes D, Guiraldes E, Hyams JS, Staiano A, et al. Childhood functional gastrointestinal disorders: child/ adolescent. Gastroenterology. 2006;130(5):1527-37.

2. Di Lorenzo C, Colletti RB, Lehmann HP, Boyle JT, Gerson WT, Hyams JS, et al. Chronic Abdominal Pain In Children: a Technical Report of the American Academy of Pediatrics and the North American Society for Pediatric Gastroenterology, Hepatology and Nutrition.J Ped Gastroenterol Nutr. 2005;40(3):249-61.

3. Loening-Baucke V. Prevalence, symptoms and outcome of constipation in infants and toddlers.J Ped. 2005;146(3):359-63.

4. Saps M, Bolioli P, Espana M, Marshall BM, Di Lorenzo C. Cost and consultation patterns of abdominal pain in Uruguayan children.J Ped Gastroenterol Nutr. 2008;46(2):159-63.

5. Roshandel D, Rezailashkajani M, Shafaee S, Zali MR. A cost analysis of functional bowel disorders in Iran. Int J Colorectal Dis. 2007;22(7):791-9.

6. Tar BA, Steurer J. [Diagnostic costs of various symptoms and disease pictures]. Praxis (Bern 1994). 1998;87(50):1741-8.

7. Liem O, Harman J, Benninga M, Kelleher K, Mousa H, Di Lorenzo C. Health utilization and cost impact of childhood constipation in the United States. J Ped. 2009;154(2):258-62;154(2):258-62.

8. Coleman WL, Levine MD. Recurrent abdominal pain: the cost of the aches and the aches of the cost. Ped Rev.1986;8(5):143-51.

9. Fullerton S. Functional digestive disorders (FDD) in the year 2000--economic impact. EurJ Surg Suppl.1998;(582):62-4.

10. Moayyedi P, Mason J. Clinical and economic consequences of dyspepsia in the community. Gut. 2002;50(Suppl 4):iv10-2. 